\title{
Theory of Multiple Intelligences and Their Application in Medicine
}

\author{
Jimenez $\mathrm{L}^{*}$ \\ Researcher in Neuroscience, Private medical practice, Venezuela
}

*Corresponding author: Luis Jimenez, Medical Doctor / Researcher in Neuroscience, Private medical practice, Venezuela, Email:

\section{Mini Review}

Volume 2 Issue 5

Received Date: November 11, 2017

Published Date: December 04, 2017

luisjimenez@neurosocietatem.com

\section{Introduction}

Since the end of the 70s a number of researchers in the area of psychology were members of a generation of pioneers who gave new views regarding the mind, behavior and intelligence as measurable and quantifiable elements, but also how these elements were not alone or isolated, it was rather the rediscovery of how these diverse properties are intertwined in a harmonious way; as time passed, names like: Howard Gardner, Daniel Goleman, Daniel Siegel, Tony Buzan, Christina Maslasch and more recent Rafael Yuste, to mention a few, were contributing to this change, these researchers and their contributions that seem distant are that they aim to a greater understanding of the human mind and its functioning.

During the pre and postgraduate medicine studies together with the clinical exercise, for different reasons: hourly load, number of hours of work and study, there tends to be isolation from other scientific branches and we lose the ability to exchange information that can help us understand our patients and even ourselves.

\section{Development}

The mind field of study and treatment of psychiatry together with psychology; the neurons and their functioning are fields of neurology, internal medicine and neurosurgery, but; what specialty studies human behavior when it is subject to specific changes and these affect the brain architecture? How can we explain outbursts of anger from the amygdala? It seems that the neurosciences interdisciplinary field takes the helm in this search.

The mind has always been the subject of debate and often we take the brain as its seat, but in the current scientific moments such as: Rafael Yuste is conducting brain mapping studies, where the functions that we have long attributed are based to our mind; This forces us to question ourselves as to whether everything we think we know about the brain and how it works is totally true, as with this concept that of intelligence is another one of those discussed. Daniel Goleman [1] in his first books argued that the perception of a single intelligence is being modified.

These concepts deserved a major study and one of the iconic scientists in his evaluation was Howard Gardner who was one of the postulants of the theory of multiple intelligences. These theories as concepts have already been put into practice in various regions of the world and have ceased to be only a subject of study and are being part of realities such as the Zero project at Harvard or countries like Singapore [2] where ways of developing these capacities contained in multiple intelligences as part of their basic and secondary education, but what about medicine? Is it impossible to bring these advances to the field of medical training? The medical profession has a great burden of archetype as Jung would say: "a task with profound emotional implications"[3-5].

The objective of this article is to show that knowledge is intertwined and is not isolated. What is intelligence? Traditionally, a common intelligence concept has been the ability of an individual to solve problems that arise in their environment. For several decades a test was used which evaluated the linguistic and mathematical capacities as a tool to try to quantify them, but what happened to those people who were not in the acceptable levels in both? Should they be removed? How to know if we could determine its useful value to society? Gardner who decided to propose explanations to questions that many had, was in the year 1983 when in his book Frames of Mind promotes a discussion of the concept of 


\section{Psychology \& Psychological Research International Journal}

intelligences that to this day give a broad view of this topic. This author describes as intelligences that necessary ability to solve problems or to elaborate products that are of importance in a cultural context or in a determined community, together with the existence of 8 types of intelligences and these would be:

\section{Kinetic-Body Intelligence}

That which manifests itself through motor skills in a coordinated and refined way, as we can see in sports and martial arts practitioners. The control of the movements is located in the motor areas of both cerebral hemispheres, but when this ability acquires the faculty of becoming a means of expression there is the key to consider it intelligence. Think of general surgeons or pediatricians with long years of practice, their movements many times invisible to the inexperienced eye because they carry a refinement of the practice and the desire for an impeccable execution.

\section{Logical Intelligence - Mathematics}

It is manifested in the ability to use logical algorithms leads us to solve problems and questions that we have, from how the replication of a virus works or because the immune system is shared in such a specific way before an antigen. The scientist faces a question and has to discard possible ways to execute the best response.

\section{Linguistic Intelligence}

It is a unique ability to be able to give sentences a meaning that can communicate the information that needs to be disseminated. This faculty is expressed by the facility to communicate ideas apart from those who possess them. This is typical of some writers such as Cervantes, Dante, Alexander Dumas but also those men and women who described in anatomy and physiology treatises knowledge that formed us in our different classrooms of pre or post degree, the ability to verbalize found in the Brocca area, when it is injured by a stroke, it will be a clear example of what this capacity lacks.

\section{Space Intelligence}

Keeps special relationship with the ability to be located in space with the elements around us, be devoid of this ability at night on the way home after a 24-hour guard would be no less than a catastrophe. However, in the middle of a mountain or an incident of danger rescuers and emergency personnel achieves what the common not, be located as speed, thus achieving the execution of their rescue maneuvers. This ability is examined with deep emphasis on neurological and psychiatric semiology.

\section{Interpersonal Intelligence}

As a skill it stands out for being able to interpret the emotions, ideas and gestures of other people. That way we can communicate in the most effective way. Being the head of a service such as internal medicine, pediatrics, surgery or obstetrics means having deputy, residents, pre-graduate interns, nursing graduates in charge; means dealing with different personalities and not to mention emotional states, but that clinical eye capable of knowing that a member of our team did not understand the instructions and how to make corrections on time or use a friendly but firm tone of voice at the right time, fact that will allow us to make our work something much more useful.

\section{Intrapersonal Intelligence}

It is a necessary capacity but rarely taken into account for the understanding of such a complex world as is the internal one, the understanding of one's own emotions and their repercussions give a greater capacity to live more fully, the Impossibility to understand emotions (atimia) is a clear example of what would be the lack of this tool. The frontal lobes have a deep relationship with the self-identification, the injury of these are a clear example of its nonexistence.

\section{Musical Intelligence}

Is the ability to recognize musical notes and their differences, the ability to organize them in an orderly way producing musical entities, many examples Beethoven, Mozart, Erick Clapton, hearing ability is not clearly recognized. In medicine, listening to a fetal heartbeat or a gallop murmur is without doubt the application of this ability.

\section{Ecological Intelligence}

It is one that contains the ability to interpret the environment, our environment quickly and clearly, to read more of this skill the trackers and hunters would be a great example who achieves a precise knowledge of the environment that surrounds them. This skill in public health personnel or field staff is a very valuable tool.

These capacities or intelligences are not separated from each other, individuals have more or less affinity for one or several of these intelligences, but as the subject develops and the conditions of the medium allow it, it will make use of the same. Currently, we observe how there is a greater possibility of being able to access information, but the development of these capabilities continues to be individual, there are techniques and methods of exploring 


\section{Psychology \& Psychological Research International Journal}

these talents as ways to develop them, in medicine being able to develop these capabilities is not impossible, perhaps some other initiative in the future can develop more studies based on this interesting topic.

\section{Conclusion}

Dear reader I am aware of the limitations of this article, it is also my desire to damage the techniques of the scientific method only to expand the understanding of a subject which is exciting and should not be limited to the psychological area as multiple intelligences.

The neurosciences an interdisciplinary field that today brings us together many scientists who on other days would not even think about sitting together at the same table, being able to meet and expand our horizons is a need that we all share, in this case medicine and the formation of new generations How can they benefit from these concepts and theories? , is the discussion we want to promote.
When writing this article from personal experience I am aware that there may be inclination to an area but I leave this message dear reader, do not limit yourself to these words search, compare and expand these theories that the point of union of all scientists continue to grow and evolving.

\section{References}

1. D Goleman (1997) Inteligencia Emocional. Barcelona, España. Kairos.

2. Gardner, Davis (2015) La generación APP. España. Paidos.

3. Jung (1990) El hombre y sus símbolos. España, Caralt.

4. Guyton y Hall (2012) Compendio de Fisiología Médica. 12 ediciones, Elsevier Saunders.

5. H Gardner (1992) Inteligencias Múltiples. España. Paidos. 